\title{
Distorted Physical Model to Study Sudden Partial Dam Break Flows in an Urban Area
}

\author{
M. S. Güney ${ }^{1}$; G. Tayfur²; G. Bombar ${ }^{3}$; and S. Elci ${ }^{4}$
}

\begin{abstract}
A distorted physical model, based on Ürkmez Dam in Izmir, Turkey, was built to study sudden partial dam break flows. The distorted model had a horizontal scale of $1 / 150$ and a vertical scale of $1 / 30$, containing dam reservoir, dam body, and downstream area-from dam body to Ürkmez urban area until the sea coast. In the model, the reservoir is approximately $12 \mathrm{~m}^{3}$, the dam body has a width of $2.84 \mathrm{~m}$ and a height of $1.07 \mathrm{~m}$, and the downstream area is nearly $200 \mathrm{~m}^{2}$. The Ürkmez Dam was chosen because Ürkmez Town is located right at its downstream area, allowing the study of dam break flows in an urban area. Furthermore, the dimensions were suitable such that it allowed the construction of a physical model (dam reservoir, dam body, and downstream area) having a horizontal scale of 1/150 in the available space of $300 \mathrm{~m}^{2}$. The features creating roughness such as buildings, bridge, and roads were also reflected in the physical model. The dam break flow was investigated for sudden partial collapse, which was simulated by a trapezoidal breach on the dam body. The water depths at downstream area were measured at eight different locations by using $e+$ WATER L (level) sensors. The velocities were measured at four different locations by ultrasonic velocity profiler (UVP) transducers. The propagation of the flood was recorded by a high-defnition camera. The experimental results show that the Ürkmez area can be flooded in a matter of minutes, at depths reaching up to $3 \mathrm{~m}$ in residential areas in $4 \mathrm{~min}$. The flood wave front can reach the residential areas in $2 \mathrm{~min}$ and to the sea coast in $4 \mathrm{~min}$. Flow velocities can reach $70.9 \mathrm{~km} / \mathrm{h}$ in sparse residential areas, close to dam body. Away from the dam body in the sparse buildings part of the town, the velocities can reach $27.7 \mathrm{~km} / \mathrm{h}$. In dense residential areas of the town, the velocities are too low $(2.8 \mathrm{~km} / \mathrm{h})$ but flow depths can reach $3 \mathrm{~m}$. Velocity profiles show similar behavior like unsteady and nonuniform open channel flow in nonresidential areas close to the dam body. In residential areas away from the dam body, the velocity profiles are more uniform, having lower velocity values. Vertical variations of velocities show markedly different behavior during rising and recession stages. The profiles are smooth during the rising stage in sparse residential area, yet it shows fluctuating behavior during the recession stage. DOI: 10.1061/(ASCE)HY.1943-7900.0000926. () 2014 American Society of Civil Engineers.
\end{abstract}

Author keywords: Distorted physical model; Dam break flows; Sudden partial collapse; Flood propagation; Flow depths; Velocity profiles.

\section{Introduction}

Dams, which are crucial hydraulic structures, providing power, irrigation, recreation, and fishery, can have disastrous effects when they collapse. Dam breaks can happen due to insufficient spillway capacity, structural defects, unstable slopes, earth slides, seepage and piping, overtopping, and earthquakes. A total of 38, 33, and $23 \%$ of dam failures are, respectively, due to insufficient spillway capacity, seepage and piping, and one or more of the other causes (Bozkus 2004; Yanmaz and Beser 2005). For example, the St. Francis Dam, a concrete arch dam with dimensions of 213-m crest length and 62.5- $\mathrm{m}$ height and 46.9 million $\mathrm{m}^{3}$ reservoir volume, in Los Angeles collapsed in 1928 due to seepage from right side and bottom of the dam (Molu 1995). Malpasset Dam in France with 222-m crest length, 66.5-m height, and 50.8 million $\mathrm{m}^{3}$

${ }^{1}$ Professor, Dept. Civil Engineering, Dokuz Eylul Univ., Tinaztepe, 35160 Izmir, Turkey. E-mail: sukru.guney@deu.edu.tr

${ }^{2}$ Professor, Dept. Civil Engineering, Izmir Institute of Technology, Urla, 35430 Izmir, Turkey (corresponding author). E-mail: gokmentayfur@iyte .edu.tr

${ }^{3}$ Assistant Professor, Dept. Civil Engineering, Ege Univ., Bornova, 35040 Izmir, Turkey. E-mail: gokcen.bombar@ege.edu.tr

${ }^{4}$ Associate Professor, Dept. Civil Engineering, Izmir Institute of Technology, Urla, 35430 Izmir, Turkey. E-mail: sebnemelci@iyte.edu.tr

Note. This manuscript was submitted on November 5, 2013; approved on June 9, 2014; published online on July 22, 2014. Discussion period open until December 22, 2014; separate discussions must be submitted for individual papers. This paper is part of the Journal of Hydraulic Engineering, (C) ASCE, ISSN 0733-9429/05014006(11)/\$25.00. reservoir volume broke down in 1959 (Molu 1995). Vajont Dam, a concrete arch dam with 267-m height in Venice, Italy, collapsed in 1963. It was the most disastrous event in dam failure history with a death toll of more than 2,000 people. The reason turned out to be the inappropriate geological site location where there the overtopping of the dam occurred as a result of a massive landslide, causing a tsunami in the lake (Molu 1995). Teton Dam, an earth-fill dam in Idaho-950-m crest height and 7.65 million $\mathrm{m}^{3}$ reservoir volume-collapsed in 1976. The reason was geological factors and ill designs such that there was seepage through the core material in the central part of the dam body (Molu 1995). The rock-fill Tous Dam in Spain, as a result of heavy rainfall, broke down in 1982, resulting in flooding of $300 \mathrm{~km}^{2}$ of inhabited land, towns, and villages. Flood depths had reached up to $7 \mathrm{~m}$ and 200,000 people were affected, of which 100,000 were already evacuated and the total death toll was 8 (Alcrudo and Mulet 2007). Big Bay Dam, which is an earth-fill 576-m long and 15.6-m high, in Lamar County, Mississippi, failed in 2004 in the vicinity of the principal spillway 12 years after construction. When the failure occurred, 17.5 million $\mathrm{m}^{3}$ of water was released, inundating $23 \mathrm{~km}$ of valley to depths of up to $10 \mathrm{~m}$ from the dam to the Pearl River (Yochum et al. 2008). Woody material was stripped from the stream valley for a length of $700 \mathrm{~m}$ immediately below the dam, after which velocities decreased to such an extent that little vegetation was uprooted (Yochum et al. 2008).

Due to better planning, design, and applications, there are few dam failures, compared to the number of existing dams, in recent decades. However, an increase in population living downstream of dams makes such dam failures very dangerous events. For example, 
on March 26, 2009, in Indonesia, an earth-fill dam-10-m height, 20 million $\mathrm{m}^{3}$ reservoir volume-due to intense rainfall collapsed, resulting in the loss of more than 100 lives and flooding hundreds of houses.

There exist various experimental dam break studies in the literature. While the majority of these studies concentrate on the failure mechanisms, a few investigate flood propagation at downstream section. The physical dam break flow experiments in the literature have generally involved flume experiments. In long and large flumes, the break experiments have been carried out by the lifting of a plate (Minussi and Maciel 2008; Palumbo et al. 2008; Cagatay and Kocaman 2008; LaRocque et al. 2013a, b). For example; Leal et al. (2002) used a rectangular 19.2-m-long, 0.5-m-wide, and 0.70-m-high channel and a movable plate. Vasquez and Leal (2006) used a $2.40 \times 2.40 \mathrm{~m}$ reservoir connected to an 8-m-long and 0.5 -m-wide rectangular flume. They generated flood by lifting the plate at the reservoir end and observed flood propagation in the flume. Greco et al. (2008) built a 0.35-m-wide and 0.37-m-high trapeozoidal sand-fill dam body in a flume for experiments. Morris et al. (2008) built a 6-m-high earth-fill dam body in a field downstream of an actual dam to study dam breaching. They also built the same dam in a small scale in a laboratory to carry out dam break flow experiments. They investigated the primary cause of structural failure. Frazao (2007) investigated dam break wave over a triangular bottom sill using a 1-m-wide and 15.5-m-long upstream reservoir in a 38-m-long channel. He investigated adverse and steep slopes with complex refractions and multiple changes in flow regime. Frazao and Zech (2007) investigated dam break flows over a single obstacle, using the same setup as in Frazao (2007). Just recently, LaRocque et al. (2013a) carried out physical dam break flow experiments in a 7.31-m-long, 0.18-m-wide, and 0.42-m-deep smooth wooden flume with a bottom slope of $0.93 \%$. By lifting the gate, they investigated instantenous dam failure.

Physical dam break flow models studying flood propagation in two dimensions over varying topography and land use are quite rare in the literature. Testa et al. (2007) carried out laboratory dam break flows in a simplified urban district. Their experimental setup involved a 50-m-long concrete model of a river with high topographical detail fitted with water depth gauges at certain locations. Flooding of the model was achieved by rapidly raising the water level in a feed tank located at the upstream end of the model by means of an electornically driven pump. The urban district was simply reflected by the $15 \mathrm{~cm}$ side of cubic concrete blocks. The 14 blocks were used to represent the district and they aligned either with the flow or staggered. In their study, although topography of the downstream area is replicated at a certain degree, the dam reservoir topography and the urban district were not actaully reflected in the physical model. Just recently, LaRocque et al. (2013b) investigated urban flooding by a levee breach. They conducted experiments on a 1/150-scale physical model of the area surrounding the 17th Street Canal breach in New Orleans. They measured steady-state flow depths and velocities in the residential area, which was represented by a total of 22 blocks.

The experimental works in the literature have significantly contributed to understanding of the dam failure mechanism and the flood propagation in one and two dimensions mostly over smooth and movable surfaces. Idealized conditions in the physical models would not, however, actually reflect the reality in the field. Therefore, there is a need to investigate dam break flow propagations over actual topographic and rough surfaces. This would require the reflection of actual dam reservoir and downstream area in the physical model. To the best knowledge of the authors of this study, there is no such detail experimental physical modeling work in the literature. One of the main reasons may be the necessity of the construction of a distorted physical model in order to carry out such experiments. Otherwise, the vertical dimensions would be too small compared with the horizontal ones such that one can not generate desirable flow depths and velocities. For example; if the physical model in this study were to have the same scale in horizontal and vertical directions $(1 / 150)$, then the maximum flow depth in the dam reservoir would be $20 \mathrm{~cm}$, which is not deep enough to cause flow depths and velocities that can be measured with sufficient accuracy in the downstream area of $200 \mathrm{~m}^{2}$. Building a distorted model is, on the other hand, costly, time consuming, and tedious work. Furthermore, it brings about issues regarding the velocity, time, and roughness scales. In other words, it requires extra care in detailed construction procedure and conversion of the parameters and variables in the model to those in the prototype.

The objectives of this paper are (1) to build a distorted physical model of Ürkmez Dam, Izmir, Turkey, reflecting actual dam reservoir and downstream area, including Ürkmez town; (2) to study flow propagation through visualization and measurements of flooding on a distorted physical model of flooded residential area; and (3) to provide a comprehensive data set on a complex free surface flow in an urban area for verifying numerical models.

\section{Design of Distorted Physical Model}

The distorted physical model of Ürkmez Dam with its reservoir and downstream area was designed to investigate two-dimensional flood wave propagation as a result of a dam failure. Ürkmez Dam is selected because it is a moderate size earth-fill dam with residential area right on its downstream side (Fig. 1). The boundaries of the area in the physical model and the chosen coordinate axes are also shown in Fig. 1.

The physical model is designed according to the Froude similarity law because the gravitational force is dominant. It is stated in Vischer and Hager (1997) that "... dambreak flows follow essentially the Froude similarity law provided that the initial flow depth $\left(h_{0}\right)$ is at least $300 \mathrm{~mm}$. Then, effects of surface tension and viscosity are negligible, at least up to 30 to 50 times $h_{0}$ downstream of the dam section...." In this study, $h_{0}$ is $840 \mathrm{~mm}$, implying that the Froude similarity law is valid at least $30 \times 0.84=25.2 \mathrm{~m}$ in the downstream part. The distance between the dam body and the downstream end of the physical model is nearly $16 \mathrm{~m}$, justifying the use of the Froude similarity law.

The horizontal and vertical scales of the model were selected so that it can be built and operated conveniently and still be big enough to measure flow depths and velocities with sufficient accuracy. According to the available space $\left(300 \mathrm{~m}^{2}\right)$ in the open area of the Hydraulics Laboratory of Dokuz Eylül University, Izmir, Turkey, the horizontal and vertical scales were selected as $1 / 150$ and $1 / 30$, respectively, and thus the distortion coefficient is $1 / 5$. The geometric characteristics of Ürkmez Dam (prototype) and its distorted physical model are given in Table 1.

\section{Velocity and Time Scales}

First horizontal and vertical scales, respectively, will be presented as $S\left(L_{x}\right)=1 / 150$ and $S\left(L_{z}\right)=1 / 30$. Thus, the distortion ratio becomes $D\left(L_{r}\right)=S\left(L_{x}\right) / S\left(L_{z}\right)=1 / 5$. The Froude number needs to be satisfied for both the prototype and the physical model and thus

$$
\frac{V_{m}}{\sqrt{g L_{z m}}}=\frac{V_{p}}{\sqrt{g L_{z p}}}
$$




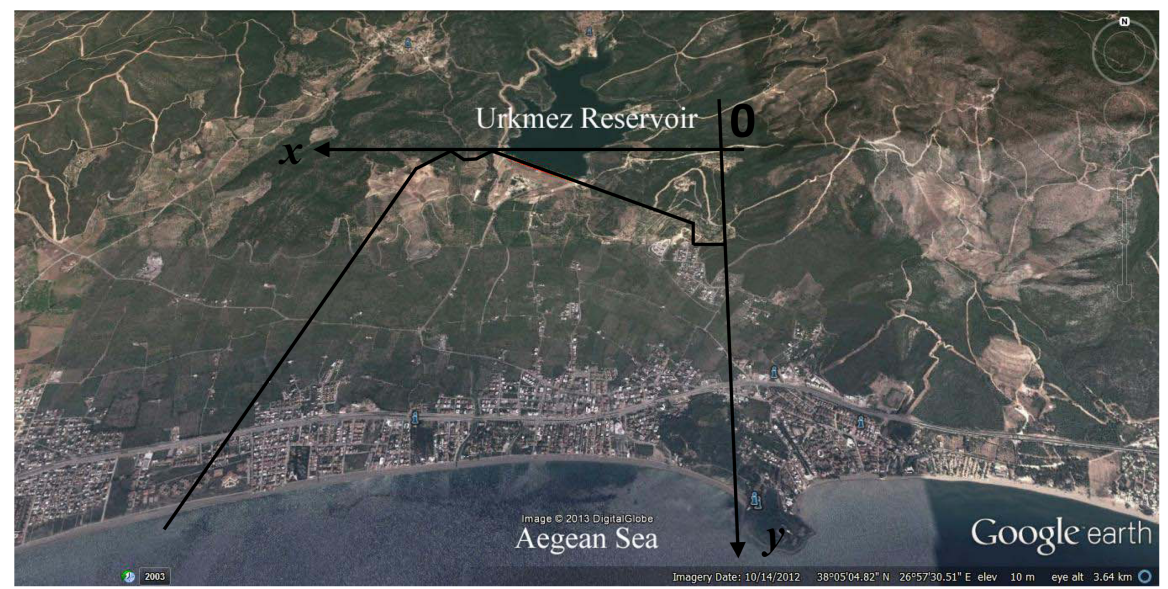

Fig. 1. General view of the studied area (Map Data: Google, DigitalGlobe)

Eq. (1) can be written as follows:

$$
\frac{V_{m}}{V p} \frac{\sqrt{L_{z p}}}{\sqrt{L_{z m}}}=1
$$

Rewriting Eq. (2) gives

$$
S(V)=S\left(L_{z}\right)^{0.5}
$$

where $S(V)=V_{m} / V_{p}$ and $S\left(L_{z}\right)^{0.5}=\sqrt{L_{z m} / L_{z p}}$.

According to Eq. (3), the velocity scale for the distorted model in this study becomes $S(V)=\sqrt{1 / 30}$. This implies that $V_{p}=5.48 V_{m}$.

The Strouhal number should be satisfied for the distorted physical model and the prototype (Yalin 1971)

$$
\frac{V_{m} T_{m}}{L_{x m}}=\frac{V_{p} T_{p}}{L_{x p}}
$$

Eq. (4) can be expressed as follows:

$$
\frac{V_{m}}{V_{p}} \frac{T_{m}}{T_{p}} \frac{L_{x p}}{L_{x m}}=1
$$

Eq. (5) can be stated as

$$
S(V) S(T)=S\left(L_{x}\right)
$$

where $S(T)=T_{m} / T_{p}$ and $S\left(L_{x}\right)=L_{x m} / L_{x p}$.

Solving Eq. (6) for $S(T)$ first and then making the use of Eq. (3) would yield the time scale as follows:

$$
S(T)=S\left(L_{x}\right) / S\left(L_{z}\right)^{0.5}
$$

Table 1. Geometric Characteristic of the Prototype and Its Physical Model

\begin{tabular}{lcc}
\hline Characteristics & Prototype & $\begin{array}{c}\text { Physical } \\
\text { model }\end{array}$ \\
\hline Crest length & $426 \mathrm{~m}$ & $2.84 \mathrm{~m}$ \\
Crest width & $12 \mathrm{~m}$ & $0.08 \mathrm{~m}$ \\
Dam height from base & $32 \mathrm{~m}$ & $1.07 \mathrm{~m}$ \\
Lake volume at minimum level & $375,000 \mathrm{~m}^{3}$ & $0.556 \mathrm{~m}^{3}$ \\
Lake volume at maximum level & $8,625,000 \mathrm{~m}^{3}$ & $12.778 \mathrm{~m}^{3}$ \\
Lake volume at normal level & $7,950,000 \mathrm{~m}^{3}$ & $11.778 \mathrm{~m}^{3}$ \\
Lake active volume & $7,575,000 \mathrm{~m}^{3}$ & $11.222 \mathrm{~m}^{3}$ \\
\hline
\end{tabular}

According to Eq. (7), the time scale for the distorted model becomes $S(T)=\sqrt{30} / 150$. In other words, $T_{p}=27.38 T_{m}$.

\section{Construction of the Distorted Physical Model}

For the drainage purpose, two 300-mm-diameter pipes were first placed in the experimental area. The bottom floor on which the physical model is constructed was first leveled, filled with fine gravel, and then compacted. After placing iron bars of 8-mm diameter, concrete was poured over the surface and it was leveled.

The cross sections of the dam reservoir and the downstream area at every $50 \mathrm{~m}$ in the downstream direction were first obtained using the related maps and then drawn for the distorted model considering the scales. Once the cross sections were drawn, they were manufactured in the laboratory using metal sheets and welding. The manufactured cross sections were placed in the experimental area at the prespecified related locations. Thus, the dam reservoir was built by placing all the metal cross sections, connecting them together. Then brick walls around the reservoir were built and the reservoir was filled with granular material. Concrete was then poured over the surface and smoothed to replicate the topography of the reservoir. The surface was treated in order to prevent any infiltration. The final view of the dam reservoir is presented in Fig. 2.

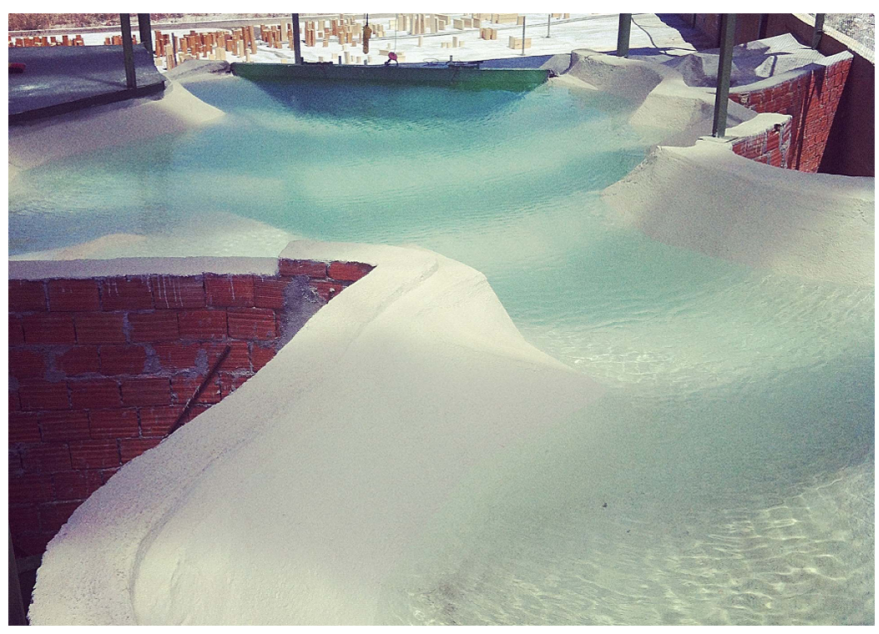

Fig. 2. View of the dam reservoir 


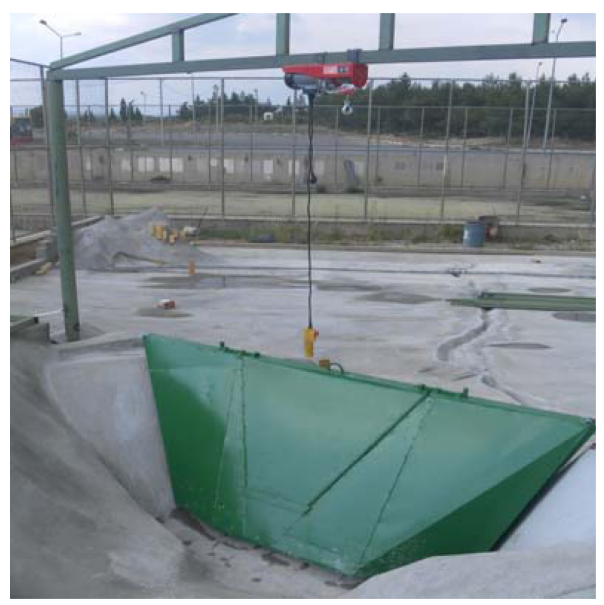

(a)
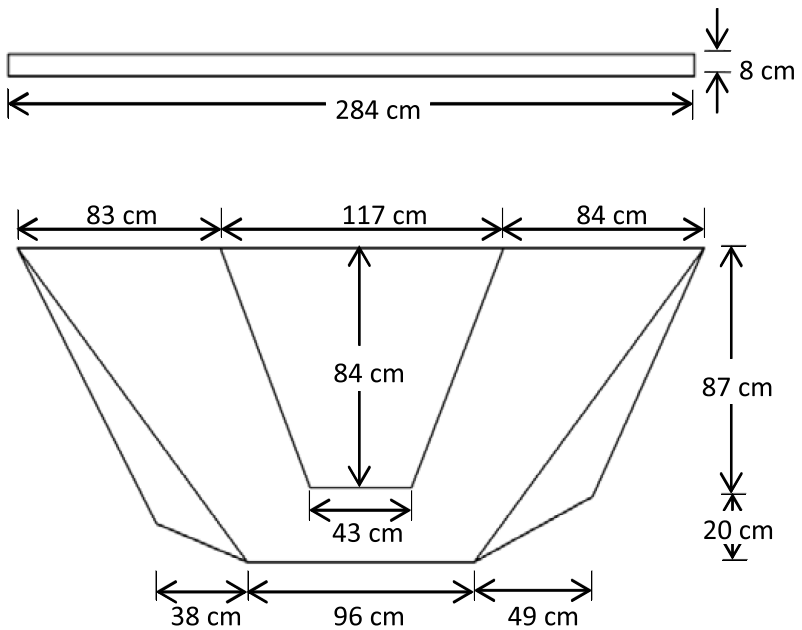

(b)

Fig. 3. (a) Dam body; (b) drawing of its detailed dimensions

The same construction procedure was continued to replicate the topography of the downstream area of the physical model, including the Ürkmez Creek. By the help of the maps obtained from Izmir Water and Sewage Department (IZSU), the residential area of Ürkmez, Turkey, was created by using wooden elements, together with the highway. The wooden blocks were cut into rectangular prismatic pieces at dimensions of residential buildings and houses, following the vertical and horizontal scales. Then each piece was glued and screwed into its respective location on the concrete floor.

Fig. 3(a) shows the dam body comprising the trapezoidal section, which was constructed by screwing the metal sheets, and the motor used to lift the body in order to create dam break. The detailed dimensions of the dam body are shown in Fig. 3(b). In order to work in any day of a season and protect the instruments, the top of the experimental site was covered by a roof. Fig. 4 presents the final stage of the completed distorted physical model for Ürkmez Dam, including reservoir, dam body, and downstream area together with Ürkmez Creek, highway, and residential area. Note that a supplementary file (Fig. S1) showing the locations (coordinates) of the buildings is provided.

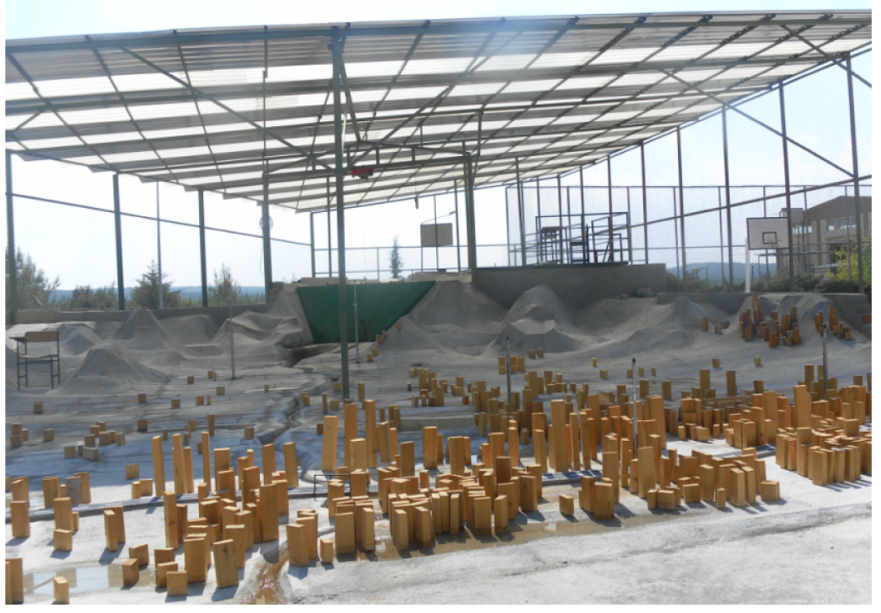

Fig. 4. Final version of the constructed distorted physical model

\section{Measurement Methods}

The reservoir was initially filled with water such that the flow depth from base to top of the dam body was $1 \mathrm{~m}$. The trapezoidal section in the middle of the dam body (Fig. 3) was then lifted by the motor to create sudden partial dam break flooding. The duration of the lift by the motor was approximately $1 \mathrm{~s}$, slightly more than $0.45 \mathrm{~s}$, which can be computed from the instantaneous gate opening formula given in Lauber and Hager (1998) and LaRocque et al. (2013a). The formula given in the literature is for the simple dambreak simulations created by the instantaneous gate opening in a flume. The distorted physical model that is presented in this paper is, however, more detailed and complex. The trapezoidal section in the dam body is too heavy as compared to a simple plate, such that the opening naturally takes a slightly longer time. As such, the authors think that the dam breaks created by the system presented in this paper can still be considered as sudden.

Flow depths were measured by e+ WATER L level sensors (http://www.eijkelkamp.com). Three level sensors were placed in the lake (L1, L12, and L13) to measure the level change in the lake and to observe any backwater movement (Fig. 5). Ten level sensors were placed in the downstream part of the model (L2, L3, L4, L5, L6, L7, L8, L9, L10, L11) (Fig. 5). The coordinates of the locations of the level sensors are summarized in Table 2. The level measurement values are automatically compensated for variations in air pressure and water density due to temperature fluctuations (EAE 2014). The L6 and L8 level meters malfunctioned such that no data were collected from these levels.

The velocities were measured at four different locations in the downstream area (V2, V3, V4, V7) (Fig. 5) by means of ultrasonic velocity profiler (UVP) and its transducers (Met-Flow 2002). The coordinates of the locations of the four UVP transducers are summarized in Table 2. The characteristics of the transducers are given in Table 3. Fig. 6 depicts the orientation of the transducers, where the values of $\alpha$ and $\beta$ angles for each transducer are summarized in Table 2. The seeding of the particles was not required because the physical model was constructed outside the laboratory and the water was full of small particles allowing the reflection of the ultrasound waves.

A high-definition (HD) camera recorded the flood propagation. The level observations at L12 and L13 showed that there were no 


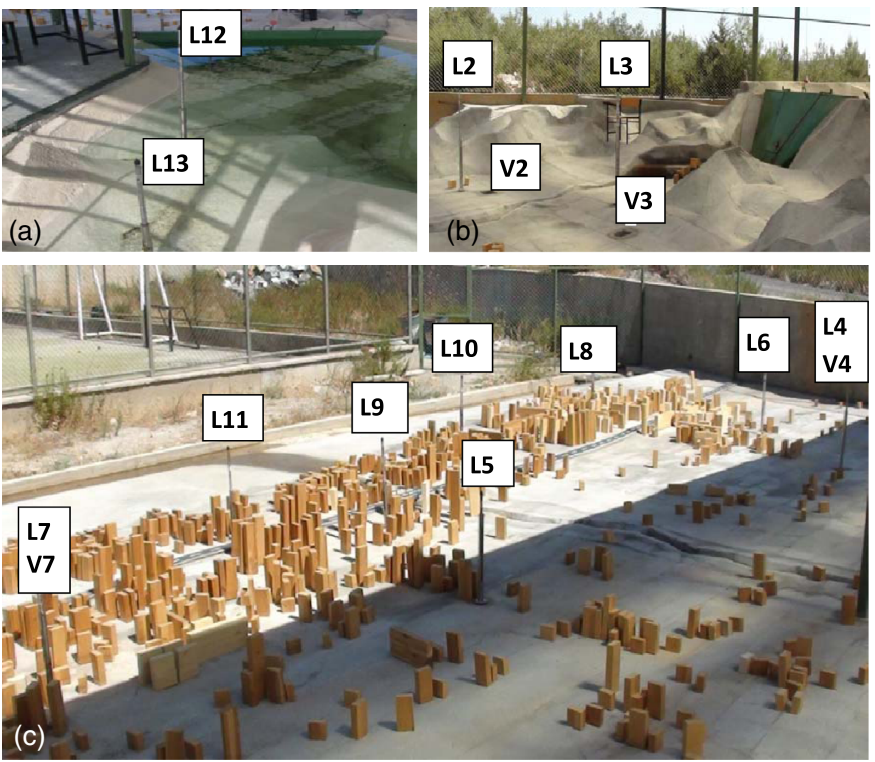

Fig. 5. Locations of level meters and UVP transducers: (a) dam reservoir (L1 is just behind L12); (b) downstream part of the dam; (c) residential area Table 2. Locations of the Measurement Devices
Coordinate System and the Values of $\alpha$ and $\beta$

\begin{tabular}{lrrrc}
\hline Instrument & $X(\mathrm{~m})$ & $Y(\mathrm{~m})$ & $\alpha\left(^{\circ}\right)$ & $\beta\left(^{\circ}\right)$ \\
\hline L2 & 8.25 & 4.44 & - & - \\
L3 & 6.43 & 3.44 & - & - \\
L4 & 11.19 & 7.24 & - & - \\
L5 & 5.83 & 9.28 & - & - \\
L7 & 2.79 & 9.96 & - & - \\
L9 & 6.50 & 11.18 & - & - \\
L10 & 10.12 & 13.18 & - & - \\
L11 & 5.88 & 11.98 & - & - \\
V2 & 8.15 & 4.34 & 8 & 28.5 \\
V3 & 6.23 & 3.64 & 9 & 0 \\
V4 & 11.29 & 7.34 & 12 & 32 \\
V7 & 2.69 & 9.86 & 7 & 24.5 \\
\hline
\end{tabular}

Note: $\alpha=$ angle with vertical; $\beta=$ angle between the line connected to the midpoint of the dam crest and $y$-axis.

Table 3. Characteristics of the UVP Transducers (Met-Flow 2014)

\begin{tabular}{lc}
\hline Property of the transducer & Defined value \\
\hline Frequency of transducers & $1 \mathrm{MHz}$ \\
Sampling period & $1.4 \mathrm{~s}$ \\
Cycles & 2 \\
Repetitions & 128 \\
Number of channels & 256 \\
Number of profiles & 1,000 \\
Amplitude data & Yes \\
Doppler data & Yes \\
Maximum depth & $192.4 \mathrm{~mm}$ \\
Window start & $0.37 \mathrm{~mm}$ \\
Window end & $189.1 \mathrm{~mm}$ \\
Channel distance & $0.74 \mathrm{~mm}$ \\
\hline
\end{tabular}

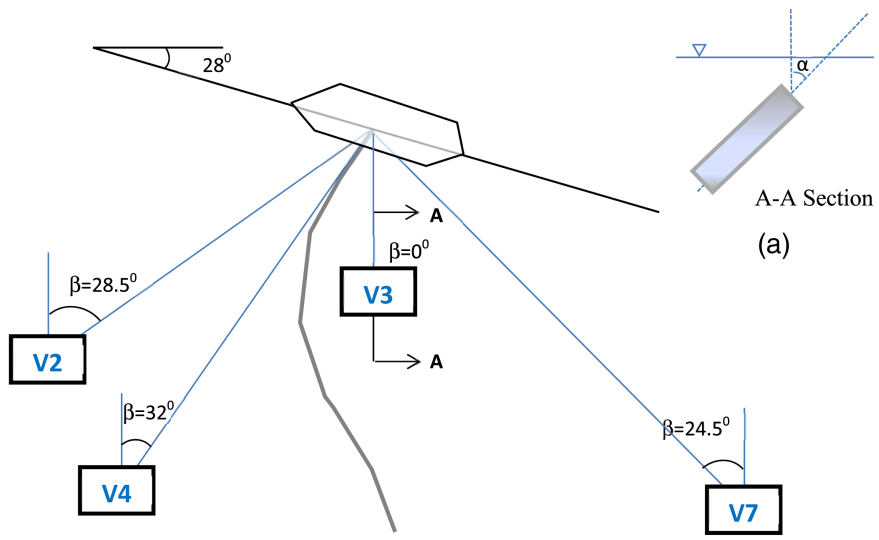

(b)

Fig. 6. Orientation of UVP transducers; angle $\alpha$ defines angle measured in vertical in cross-sectional view and angle $\beta$ defines angle measured in horizontal in planar view (angle between the line connected to the midpoint of the dam crest and $y$-axis)

backwater effects resulting from the lift of the trapezoidal section within the reservoir.

\section{Experimental Findings}

\section{Repeatability Check}

During spring of 2013, a total of five experiments were conducted to ensure that the experiments were repeatable under the same conditions where hydrograph, water level, and velocity measurements were carried out. The five flood hydrographs derived from the measurements of the level meter (L1) inside the reservoir are presented in Fig. 7(a). The root-mean-square error (RMSE) values were calculated by comparing each experiment with the averaged values of five experiments (Table 4). The maximum RMSE value was calculated as $0.0147 \mathrm{~m}^{3} / \mathrm{s}$, which was $4 \%$ of the peak discharge. Similarly, Fig. 7(b) shows the comparison of five experiments for the water levels measured at a location (L10) near the road. The maximum RMSE value for water level was $0.2155 \mathrm{~cm}$, which was also $4 \%$ of the peak water level value (Table 2). Comparison of water velocities measured at a location near the dam (V3) are provided in Fig. 7(c). The maximum RMSE value calculated for this location was $0.8796 \mathrm{~m} / \mathrm{s}$, which was approximately $10 \%$ of the measured peak velocity (Table 4). RMSE values in Table 4 and Fig. 7 confirm the repeatability of the experiments. The figures in Fig. 7 show a close match between the trials. The small differences in the figures were likely due to random fluctuations in the flow field as a result of the complex topography.

The flow depth and velocity measurements presented and analyzed in the following sections are the averages of these five experimental runs, unless stated otherwise.

\section{Flood Hydrograph and Wave Propagation}

The model reservoir volume-water depth curve was obtained by the measurements of level meter L1 (see Fig. 5, right behind L12 close to the dam body). The measured level values are converted to the volume, allowing the determination of the discharge values of the hydrograph where the discharge reaches a peak value of $0.36 \mathrm{~m}^{3} / \mathrm{s}$.

Fig. 8 shows the flood propagation recorded by an HD camera during a single experiment. As seen, the flood arrives at the 

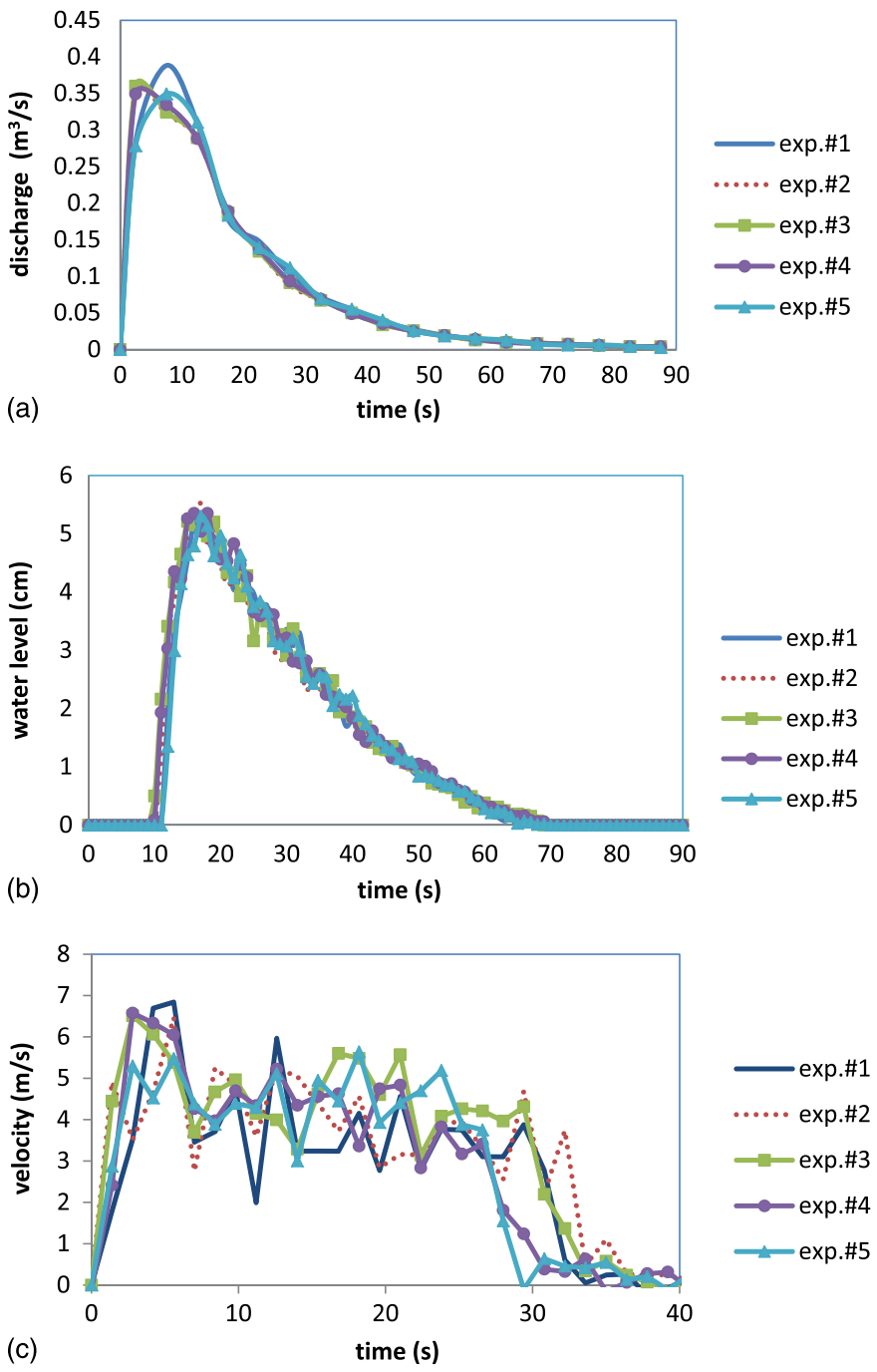

Fig. 7. Comparison of measured (a) hydrographs; (b) flow depths measured at Location 10 (L10); (c) flow velocities measured at Location \#3 (V3) from five trial experiments for checking the repeatability of the experiments

Table 4. RMSE Values for Hydrograph, Level Meter 10, and Velocity Meter 3

\begin{tabular}{lccc}
\hline \multirow{2}{*}{$\begin{array}{l}\text { Experiment } \\
\text { number }\end{array}$} & RMSE \\
\cline { 2 - 4 } & Hydrograph $\left(\mathrm{m}^{3} / \mathrm{s}\right)$ & L10 $(\mathrm{cm})$ & V3 $(\mathrm{m} / \mathrm{s})$ \\
\hline 1 & 0.0147 & 0.1760 & 0.7852 \\
3 & 0.0087 & 0.1314 & 0.8796 \\
4 & 0.0096 & 0.1914 & 0.7136 \\
5 & 0.0066 & 0.1649 & 0.6929 \\
\hline
\end{tabular}

uppermost area (the area close to dam body) in $2 \mathrm{~s}$ (in approximately $1 \mathrm{~min}$ in prototype) [Fig. 8(a)], at the residential area and the main road in $4 \mathrm{~s}$ (in approximately $2 \mathrm{~min}$ in prototype) [Fig. 8(b)], and at the sea cost in $8 \mathrm{~s}$ (in approximately $4 \mathrm{~min}$ in prototype) [Fig. 8(c)].

Some values of the water depths measured at different times are listed in Table 5, the highest values being shown in bold. Table 6 presents the corresponding values for the prototype. As seen, the values are compatible with the topography of the studied area.

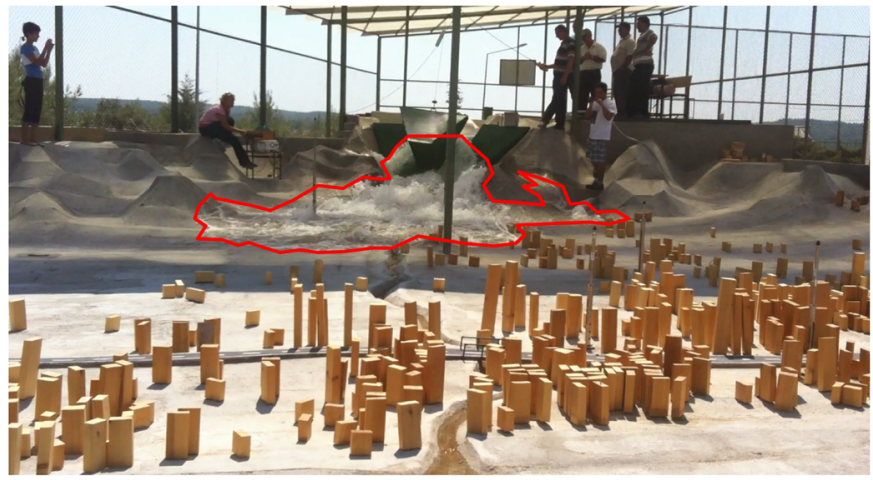

(a)

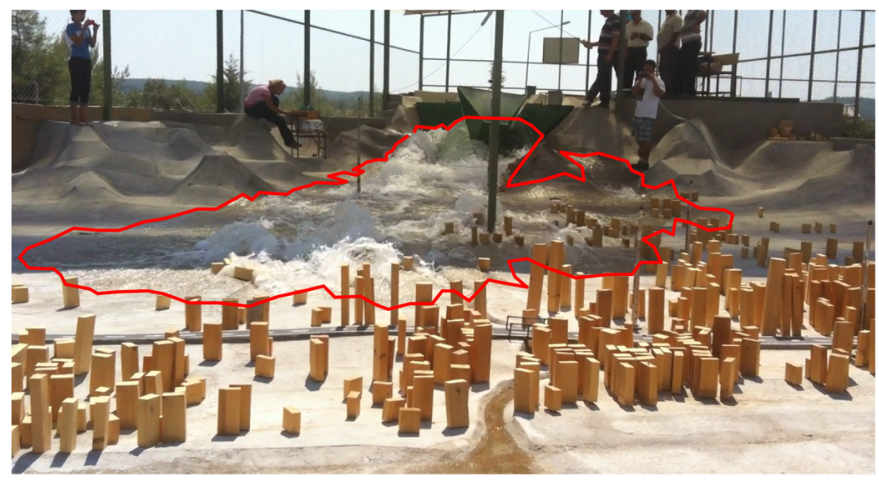

(b)

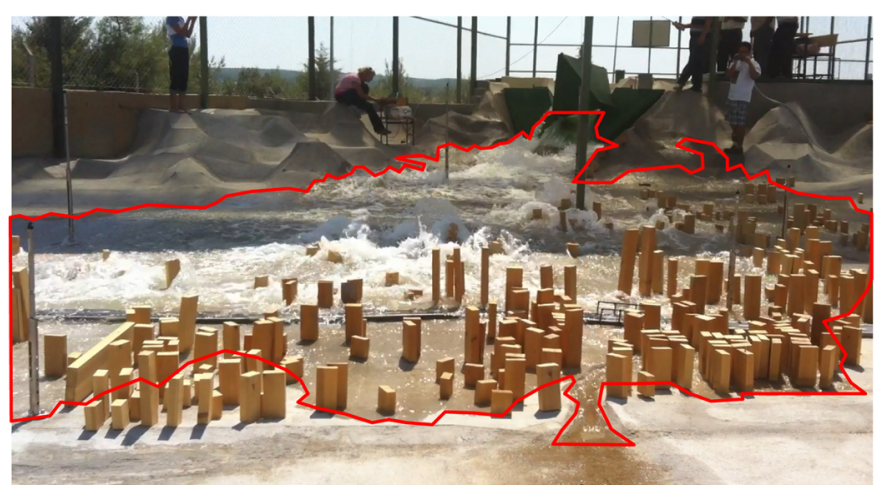

(c)

Fig. 8. Flood propagation at (a) $2 \mathrm{~s}$; (b) $4 \mathrm{~s}$; (c) $8 \mathrm{~s}$ of the experiment

Table 5. Measured Water Depths at Different Times

\begin{tabular}{lcccccccc}
\hline $\begin{array}{l}\text { Time } \\
(\mathrm{s})\end{array}$ & $\begin{array}{c}\text { L2 } \\
(\mathrm{cm})\end{array}$ & $\begin{array}{c}\text { L3 } \\
(\mathrm{cm})\end{array}$ & $\begin{array}{c}\text { L4 } \\
(\mathrm{cm})\end{array}$ & $\begin{array}{c}\text { L5 } \\
(\mathrm{cm})\end{array}$ & $\begin{array}{c}\text { L7 } \\
(\mathrm{cm})\end{array}$ & $\begin{array}{c}\text { L9 } \\
(\mathrm{cm})\end{array}$ & $\begin{array}{c}\text { L10 } \\
(\mathrm{cm})\end{array}$ & $\begin{array}{c}\text { L11 } \\
(\mathrm{cm})\end{array}$ \\
\hline 4 & - & $\mathbf{9 . 8 8 0}$ & - & - & - & - & - & - \\
5 & 8.024 & 7.512 & 0.000 & 0.000 & 0.000 & 0.000 & 0.000 & 0.000 \\
6 & $\mathbf{8 . 8 8 6}$ & - & - & - & - & 0.380 & - & - \\
10 & 7.280 & 2.364 & 4.642 & 1.672 & 0.000 & 7.670 & 0.000 & 0.000 \\
11 & - & - & - & - & - & - & - & 2.156 \\
14 & - & - & - & - & 0.278 & - & - & - \\
15 & 5.386 & 2.116 & 4.602 & 3.308 & 0.312 & $\mathbf{9 . 7 5 0}$ & 4.934 & 6.022 \\
19 & - & - & $\mathbf{5 . 9 9 0}$ & - & - & - & $\mathbf{5 . 2 4 8}$ & - \\
20 & 4.008 & 2.152 & 3.594 & $\mathbf{3 . 8 1 8}$ & 3.220 & 9.205 & 4.748 & 6.764 \\
21 & - & - & - & - & - & - & - & $\mathbf{6 . 8 3 2}$ \\
25 & 2.820 & 1.414 & 2.538 & 3.414 & 5.054 & 8.520 & 3.624 & 6.310 \\
30 & 2.086 & 0.334 & 2.376 & 3.270 & 6.086 & 7.855 & 3.064 & 5.978 \\
35 & 1.706 & 0.434 & 2.266 & 3.246 & $\mathbf{6 . 4 1 6}$ & 7.665 & 2.524 & 5.226 \\
40 & 0.964 & 0.336 & 2.128 & 3.410 & 6.240 & 7.238 & 1.922 & 4.804 \\
\hline
\end{tabular}

Note: Highest values are shown in bold. 
Table 6. Corresponding Water Depths at Different Times at Prototype

\begin{tabular}{lcccccccc}
\hline $\begin{array}{l}\text { Time } \\
(\mathrm{min})\end{array}$ & $\begin{array}{c}\text { L2 } \\
(\mathrm{m})\end{array}$ & $\begin{array}{c}\text { L3 } \\
(\mathrm{m})\end{array}$ & $\begin{array}{c}\text { L4 } \\
(\mathrm{m})\end{array}$ & $\begin{array}{c}\text { L5 } \\
(\mathrm{m})\end{array}$ & $\begin{array}{c}\text { L7 } \\
(\mathrm{m})\end{array}$ & $\begin{array}{c}\text { L9 } \\
(\mathrm{m})\end{array}$ & $\begin{array}{c}\text { L10 } \\
(\mathrm{m})\end{array}$ & $\begin{array}{c}\text { L11 } \\
(\mathrm{m})\end{array}$ \\
\hline 1.83 & - & $\mathbf{2 . 9 6 4}$ & - & - & - & - & - & - \\
2.28 & 2.407 & 2.254 & - & - & - & - & - & - \\
2.74 & $\mathbf{2 . 6 6 6}$ & - & - & - & - & - & - & - \\
4.56 & 2.184 & 0.709 & 1.393 & 0.502 & - & 2.301 & - & - \\
5.02 & - & - & - & - & - & - & - & 0.647 \\
6.39 & - & - & - & - & 0.083 & - & - & - \\
6.85 & 1.616 & 0.635 & 1.381 & 0.992 & 0.094 & $\mathbf{2 . 9 2 5}$ & 1.480 & 1.807 \\
8.67 & - & - & $\mathbf{1 . 7 9 7}$ & - & - & - & $\mathbf{1 . 5 7 4}$ & - \\
9.13 & 1.202 & 0.646 & 1.078 & $\mathbf{1 . 1 4 5}$ & 0.966 & 2.762 & 1.424 & 2.029 \\
9.58 & - & - & - & - & - & - & - & $\mathbf{2 . 0 5 0}$ \\
11.41 & 0.846 & 0.424 & 0.761 & 1.024 & 1.516 & 2.556 & 1.087 & 1.893 \\
13.69 & 0.626 & 0.100 & 0.713 & 0.981 & 1.826 & 2.357 & 0.919 & 1.793 \\
15.97 & 0.512 & 0.130 & 0.680 & 0.974 & $\mathbf{1 . 9 2 5}$ & 2.300 & 0.757 & 1.568 \\
18.25 & 0.289 & 0.101 & 0.638 & 1.023 & 1.872 & 2.171 & 0.577 & 1.441 \\
\hline
\end{tabular}

Note: Highest values are shown in bold.

Maximum flow depths reach $2.96 \mathrm{~m}$ in $1.8 \mathrm{~min}$ in very sparse residential areas near the dam body (L3). That means in $2 \mathrm{~min}$, the first floor of houses would be submerged under flood waves. In sparse residential areas (L4), flow depths reach $1.8 \mathrm{~m}$ in approximately $8.4 \mathrm{~min}$. In a dense residential area (L7), flow depths reach $2.9 \mathrm{~m}$ in $8.0 \mathrm{~min}$. That means in such areas the first two floors of the houses would be affected from flooding. In the first $10 \mathrm{~min}$ of the dam break, flow depths can reach $2 \mathrm{~m}$ in the residential area at the end of the town (L11).

Table 7 presents measured flow velocities at different times and Table 8 shows the corresponding velocity values at prototype. As seen, flow velocities reach $19.7 \mathrm{~m} / \mathrm{s}$ (70.9 km/h in prototype) in very sparse residential areas, close to the dam body (L2, V2) in $2.2 \mathrm{~min}$. In sparse residential areas (L4, V4), velocities are not too high. In $4.4 \mathrm{~min}$, the maximum velocity is $7.7 \mathrm{~m} / \mathrm{s}(27.7 \mathrm{~km} / \mathrm{h}$ in prototype). In dense residential areas (L7, V7), the velocities are very low with maximum of $0.78 \mathrm{~m} / \mathrm{s}(2.8 \mathrm{~km} / \mathrm{h}$ in prototype) in $8.8 \mathrm{~min}$.

Table 7. Measured Water Velocities at Different Times

\begin{tabular}{lcccc}
\hline Time $(\mathrm{s})$ & $\mathrm{V} 2(\mathrm{~m} / \mathrm{s})$ & $\mathrm{V} 3(\mathrm{~m} / \mathrm{s})$ & $\mathrm{V} 4(\mathrm{~m} / \mathrm{s})$ & $\mathrm{V} 7(\mathrm{~m} / \mathrm{s})$ \\
\hline 5 & 3.587 & 5.652 & 0.000 & 0.000 \\
10 & 3.229 & 4.632 & 1.401 & 0.000 \\
15 & 2.749 & 4.429 & 0.448 & 0.000 \\
20 & 2.336 & 4.162 & 0.362 & 0.142 \\
25 & 2.339 & 3.876 & 0.159 & 0.043 \\
30 & 1.812 & 2.029 & 0.084 & 0.021 \\
35 & 1.613 & 0.518 & 0.008 & 0.074 \\
40 & 0.595 & 0.092 & 0.045 & 0.068 \\
\hline
\end{tabular}

Table 8. Corresponding Water Velocities at Prototype

\begin{tabular}{lcccc}
\hline Time $(\mathrm{min})$ & $\mathrm{V} 2(\mathrm{~m} / \mathrm{s})$ & $\mathrm{V} 3(\mathrm{~m} / \mathrm{s})$ & $\mathrm{V} 4(\mathrm{~m} / \mathrm{s})$ & $\mathrm{V} 7(\mathrm{~m} / \mathrm{s})$ \\
\hline 2.2 & 19.657 & 30.970 & 0.000 & 0.000 \\
4.4 & 17.693 & 25.383 & 7.677 & 0.000 \\
6.6 & 15.063 & 24.269 & 2.453 & 0.000 \\
8.8 & 12.803 & 22.809 & 1.982 & 0.777 \\
11.0 & 12.819 & 21.238 & 0.872 & 0.238 \\
13.2 & 9.928 & 11.116 & 0.458 & 0.116 \\
15.4 & 8.840 & 2.840 & 0.042 & 0.404 \\
17.6 & 3.258 & 0.506 & 0.248 & 0.370 \\
\hline
\end{tabular}

Buildings in very sparse residential areas, close to dam body (L2, L3) can experience the highest amount of hydrodynamic pressure forces because the force depends on the velocity averaged over the impacted face of the building (LaRocque et al. 2013a, b). In sparse residential areas (e.g., Location 4) hydrodynamic pressure forces would be much less as compared with ones close to the dam body. Buildings in dense residential areas such as Location 9 would experience insignificant hydrodynamic but significant hydrostatic forces. The detailed analysis of measured flow depths and velocities are presented in the next sections.

These results refer to an incomplete model because of the model distortion and scaling, in particular in the far field.

\section{Flow Depths}

Experimental flow depths were measured by water level sensors, whose locations are presented in Fig. 5 and coordinates are summarized in Table 2. As seen in Fig. 9, the rise of flow depth at Location 2 is sudden. Around the location there are sparsely distributed houses. Flow depths reach $8.89 \mathrm{~cm}$ in approximately $6 \mathrm{~s}$. This implies that in the real field, when a sudden dam break occurs one-floor houses $(2.67-\mathrm{m}$ height $)$ can be immersed into the flood wave in approximately $2.7 \mathrm{~min}$. Similar behavior is observed for Location 3, which is near the creek and on the opposite side of Location 2 (Fig. 10). The maximum level suddenly reaches $9.88 \mathrm{~cm}$ in $4 \mathrm{~s}$ and recedes in $30 \mathrm{~s}$. This corresponds to 2.96-m maximum depth in $1.8 \mathrm{~min}$. That means the houses around this location is subject to sudden flooding in approximately $2 \mathrm{~min}$. Location 5 is in a residential area (Fig. 10). As seen, the maximum flow depth reaches $3.8 \mathrm{~cm}$ in $20 \mathrm{~s}$ and after $45 \mathrm{~s}$ it starts the gradual decrease.

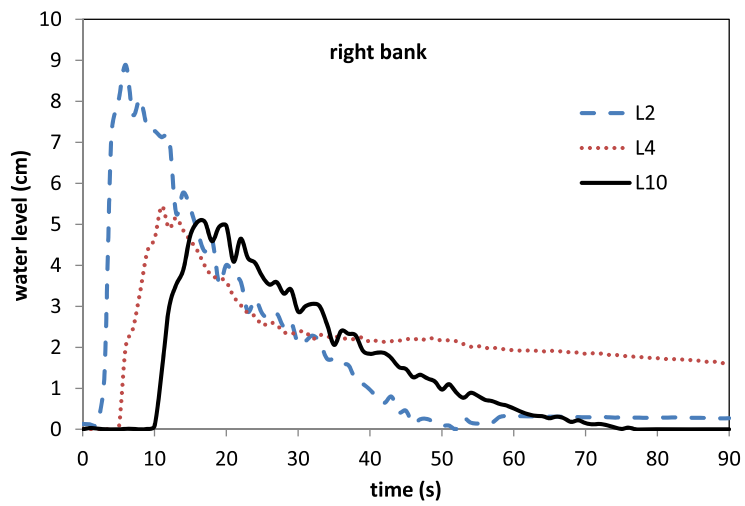

Fig. 9. Comparison of levels at Locations 2, 4, and 10

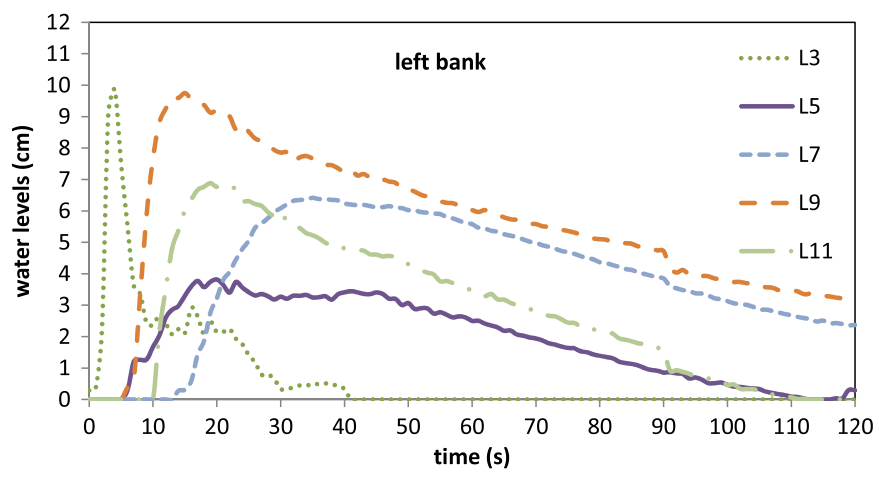

Fig. 10. Comparison of levels at Locations 3, 5, 7, 9, and 11 
That means the level stays around $3.4 \mathrm{~cm}$ for approximately $25 \mathrm{~s}$. For the prototype, this means that water levels in the residential area downtown would reach $1.15 \mathrm{~m}$ in approximately 9 min and stay at the same level for approximately $10 \mathrm{~min}$ before starting gradual receding.

The wave front reaches Location 4 in 4.6 min with levels reaching $1.4 \mathrm{~m}$ (Fig. 9). The largest flow depth of $1.8 \mathrm{~m}$ occurred $8.7 \mathrm{~min}$ after the dam break. The levels decrease gradually $30 \mathrm{~cm}$ in $30 \mathrm{~min}$. Location 7 is on the far left side (looking downward towards the sea from the dam body) of the town in a residential area (Fig. 5). The increase in the flow depth is gradual reaching a maximum of $1.93 \mathrm{~m}$ in 16 min (Fig. 10). At Location 9, which is close to the road and located in a residential area where buildings delayed the flood wave front and increased flow depths, levels reached $2.9 \mathrm{~m}$ in approximately $7 \mathrm{~min}$ (Fig. 10). Because it is a residential area, as is the case for Location 5 (Fig. 10), water levels decreased gradually to the minimum level of approximately $1 \mathrm{~m}$ in $50 \mathrm{~min}$. Location 10 is at the end of the town, on the other side of the highway near the sea coast (Fig. 5). The maximum level is $1.6 \mathrm{~m}$ and the gradual recession to zero takes approximately $30 \mathrm{~min}$ in the real case. The levels reach about $2 \mathrm{~m}$ in approximately $10 \mathrm{~min}$ at Location 11 (Fig. 10), which is located in the residential area near the road (Fig. 5). The recession in residential areas takes longer time due to the storage effects of the buildings.

Locations 2, 4, and 10 are on the right-hand side of the creek, while Locations 3, 5, 7, 9, and 11 are on the left-hand side (looking downward towards the sea from dam body). Figs. 9 and 10 present levels on these locations, respectively. According to Fig. 9, on the right-hand side of the creek the wave front reaches the first location in $1 \mathrm{~min}$ and the last location in $4.5 \mathrm{~min}$. While the rising limbs are sharp, the recession limbs are gradual. The storage effects are not enormous because the recessions take place in approximately $20 \mathrm{~min}$ in a very sparse residential area (Location 2) and $40 \mathrm{~min}$ in residential area with minimum level of $30 \mathrm{~cm}$ (Location 4). According to Fig. 10, other than Location 3, which is near the dam body in a sparse residential area, the levels in other locations increase in a short time and decrease gradually. The storage effects are dominant in this area. The decrease in general takes approximately $50 \mathrm{~min}$ and stays even in 1.2-m levels in dense residential areas (see Locations 7 and 9).

The effect of the road can be clearly seen when the levels in Locations 9 and 11 are compared (Fig. 10). As seen, the maximum level in L9 is approximately $3 \mathrm{~cm}$ higher (1 $\mathrm{m}$ in prototype) than that in L11 and the recession takes a much longer time.

\section{Flow Velocities}

Flow velocities were measured at four locations, namely, V2, V3, V4, and V7 in Fig. 5. The coordinates of the transducers are summarized in Table 2. The characteristics of the UVP transducers are given in Table 3 and the orientations of the transducers are depicted in Fig. 3 and orientation information is given in Table 2.

Measured velocity profiles show similar behavior at Locations 2 and 3 (Fig. 11). At Location 2, which is on the right bank, very sparse residential area, very close to the dam body (Fig. 5), velocity reaches $3.6 \mathrm{~m} / \mathrm{s}$ in $5 \mathrm{~s}$, then gradually decreases to $0.5 \mathrm{~m} / \mathrm{s}$ in $35 \mathrm{~s}$ (Fig. 11). At Location 3, which is on the left bank, close to the dam body (Fig. 5), velocity reaches $5.8 \mathrm{~m} / \mathrm{s}$ in $5 \mathrm{~s}$, fluctuates around $4.5 \mathrm{~m} / \mathrm{s}$ for a duration of $20 \mathrm{~s}$, then sharply decreases to $1 \mathrm{~m} / \mathrm{s}$ in $5 \mathrm{~s}$ (Fig. 11). The wave front reaches Location 4, which is in a sparse residential area (Fig. 5) at approximatley $8 \mathrm{~s}$; it then reaches $1.5 \mathrm{~m} / \mathrm{s}$ at $10 \mathrm{~s}$ and gradually decreases to $0.5 \mathrm{~s}$ in $10 \mathrm{~s}$ (Fig. 11). Location 7 is in a dense residential area (Fig. 5) where flow velocity is nearly zero (Fig. 11) due to storage effects of buildings.

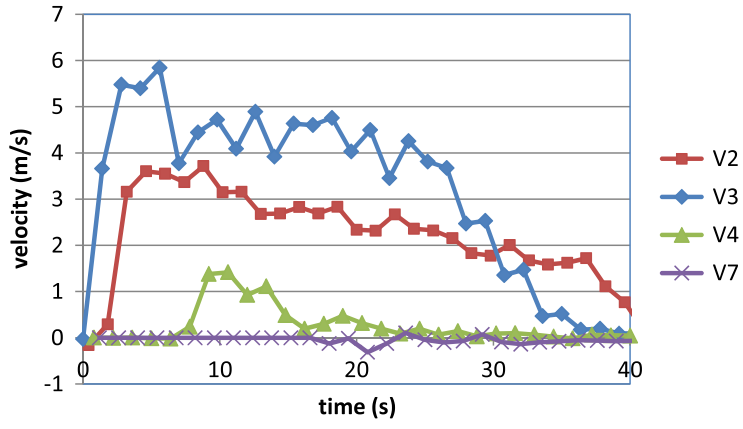

Fig. 11. Observed velocity time series at four different locations
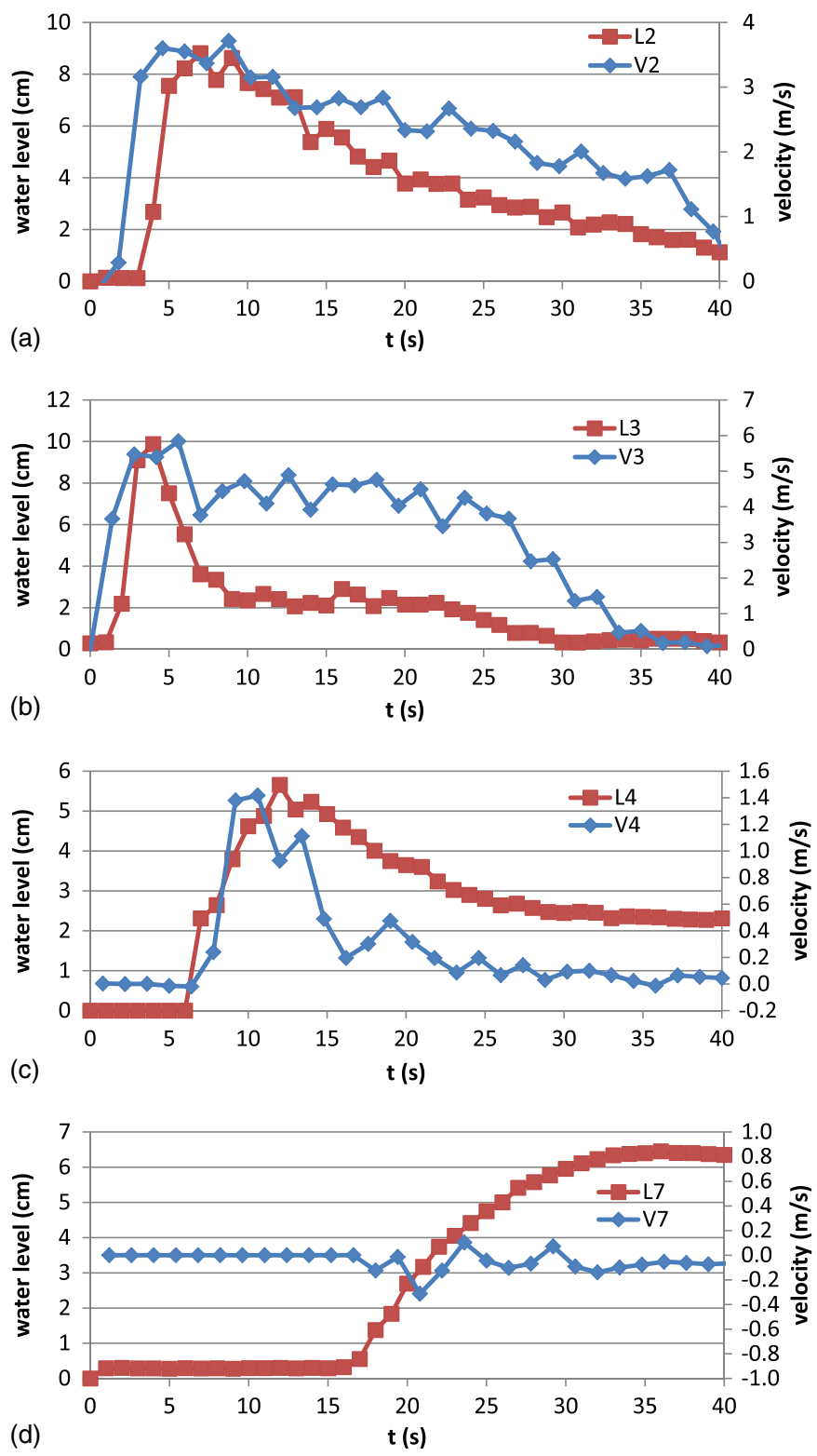

Fig. 12. Comparison of observed velocities with the observed water levels at four locations during the experiments

Fig. 12 presents measured flow depth and velocities at four locations for the period of the first 40-s duration. As seen, in very sparse residential areas (Locations 2 and 3), flow depths and velocities reach their respective peak values at around the same time. 
They have similar rising and recession profiles [Figs. 12(a and b)]. In a sparse residential area (Location 4), although the flow depth and velocity reach their respective peak values at approximately the same time, velocity in a short period of time goes to zero, while flow is stored due to the building effects [Fig. 12(c)]. In a very dense residential area (Location 7), due to the effects of building blocks, while velocity fluctuates around zero, flow depth keeps rising [Fig. 12(d)].

Velocity profiles at four locations at various times are presented in Fig. 13. The profiles presented in this section are obtained from a single experimental run. As seen in Figs. 13(a and b), profiles belonging to very sparse residential areas, namely Locations 2 and 3 , have the same behavior at peak and later times. Yet as the time
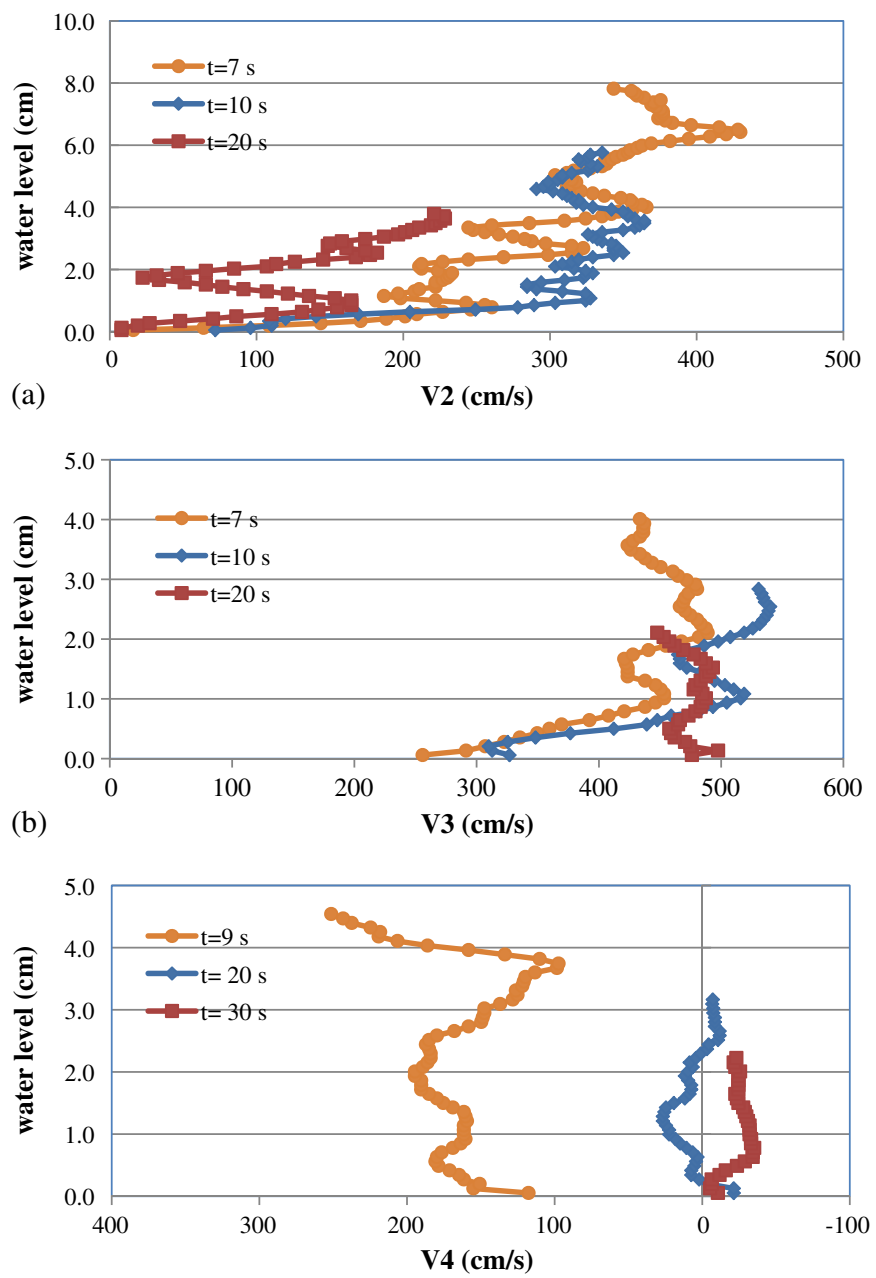

(c)

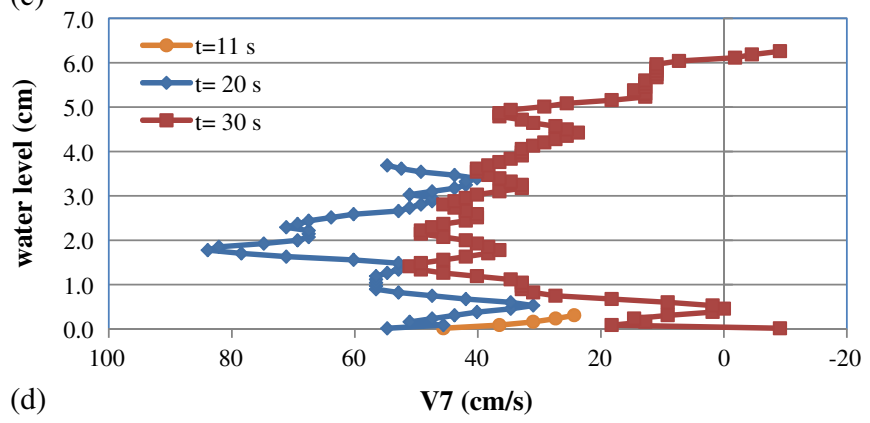

Fig. 13. Vertical variations of observed velocities at four locations at various times, where the first instant showing the profile when the peak velocity is reached prolongs, the profile becomes vertical at small depth [Fig. 13(b)]. In a sparse residential area (Location $4, \mathrm{~V} 4$ ), velocity profiles are almost vertical with high magnitude at peak time and low magnitude at later times of the experiment [Fig. 13(c)]. In a dense residential area (Location 7, V7), the velocity profiles are uniform with almost the same low magnitude during the flooding period [Fig. 13(d)].

Fig. 14 compares vertical variations of velocities during the rising and falling stages. As seen, vertical velocity profiles show markedly different behavior during rising and recession stages. The profiles are smooth during rising stage in nonresidential areas (Locations 2 and 3) but show zigzag behavior during the recession stage [Figs. 14(a and b)]. In a sparse residential area, the vertical velocity profile can be considered as smooth during the rising stage, yet it shows the same fluctuating behavior during recession stage [Fig. 14(c)]. In a dense residential area, the vertical profile is vertical, fluctuating around zero with $\pm 0.3 \mathrm{~m} / \mathrm{s}$ velocity magnitude [Fig. 14(d)] during the recession stage.

Temporal variation of Froude number values were also computed for the measured velocities and depths at the four locations. The computed values indicate that in Locations 2 and 3 (very sparse
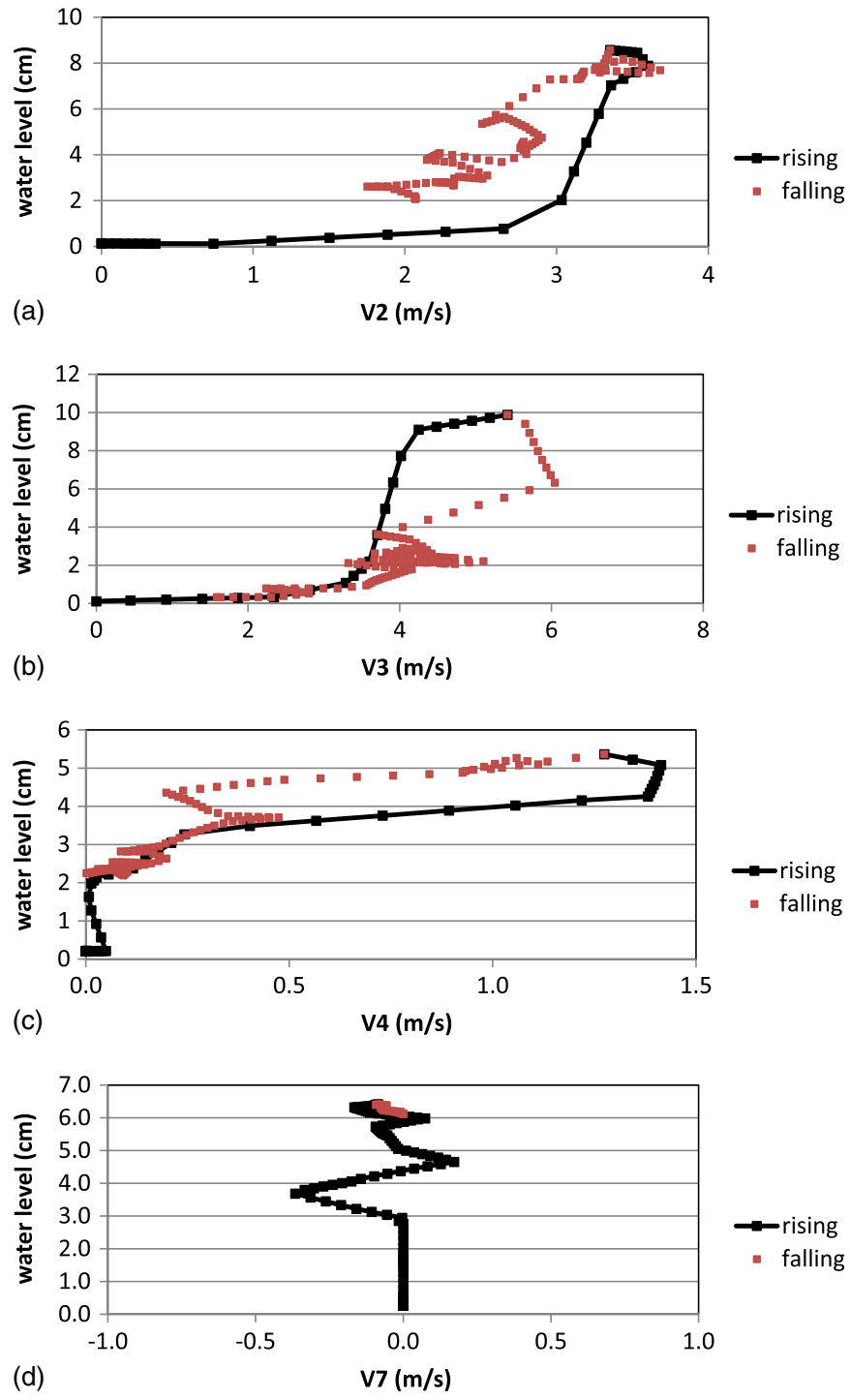

Fig. 14. Comparison of vertical variations of velocities during the rising and falling of the stages 
residential area, near dam body), the supercritical flow is dominant during the flooding. In a sparse residential area (Location 4), supercritical flow occurs for a shorter period of time due to building effects. In a very dense residential area (Location 7), flow velocities are very low and flow depths are very high and therefore flow is in subcritical conditions for the whole flooding period.

\section{Comparison with Existing Studies}

Although it is not possible to carry out one-to-one comparison with other studies because each has its unique experimental setup and characteristics, the following comparisons are presented to give an insight into the overall reasonableness of experimental results.

Testa et al. (2007) carried out several experiments in a simplified urban district built in a laboratory in Centro Elettrotechnico Sperimentale Italiano (CESI) facilities in Milan, Italy. Their experimental setup was composed of 1/100 scaled model of the Toce River Valley. They replicated the urban area in a simplified manner with cubic blocks (15-cm-long edges) aligned or staggered. The flooding of the model was achieved by rapidly raising the water level in a feed tank located at the upstream end of the model by means of an electrically driven pump. For the dam break experiments, an area $5 \mathrm{~m}$ downstream (approximately $50 \mathrm{~m}^{2}$ ) was used (Testa et al. 2007). They carried out experiments with three different flood hydrographs (peaks of 85,130 , and $185 \mathrm{~L} / \mathrm{s}$ for 60 -s duration).

The physical model of Ürkmez Dam reservoir and the downstream area is more detailed and the urban area was almost replicated one to one. The suitable comparison between the experimental works of two studies can be done for the case in which staggered blocks were used in Testa et al. (2007) with a $185 \mathrm{~L} / \mathrm{s}$ hydrograph peak. The peak hydrograph of Ürkmez Dam break physical model is approximately twice that in Testa et al. (2007), and the downstream area is much larger (approximately $200 \mathrm{~m}^{2}$ ) in the case of the Ürkmez physical model. Keeping all these in mind, they measured flow depths on the average in between 2 and $10 \mathrm{~cm}$, which are comparable with the measurements presented previously. The rising and recession profiles and periods are also comparable in both studies.

Alcrudo and Mulet (2007) described the Tous Dam break that happened in 1982 due to heavy rainfall. The dam is located on the Jucar River in the central part of the Mediterranean coast of Spain. On October 20, 1982, there was extremely heavy rainfall- $500 \mathrm{~mm}$ in $24 \mathrm{~h}$. Consequently, the dam failed. The reservoir capacity was $122 \times 10^{6} \mathrm{~m}^{3}$ at crest level. However, total rainfall volume over the basin reached almost $600 \times 10^{6} \mathrm{~m}^{3}$, largely exceeding the capacity of the reservoir. The effects of the flood downstream of the dam were catastrophic $-300 \mathrm{~km}^{2}$ of inhabited land were severely flooded. The first affected town was Sumacarcel, Spain, approximately $5 \mathrm{~km}$ downstream of the dam. The ancient part of the town is located closer to the river course and was completely flooded with high water marks reaching between 6 and $7 \mathrm{~m}$. According to Alcrudo and Mulet (2007), the outflow hydrograph from the dam had approximately $15.000 \mathrm{~m}^{3} / \mathrm{s}$ peak discharge.

Ürkmez Dam reservoir, on the other hand, has a volume of $8.63 \times 10^{6} \mathrm{~m}^{3}$ at crest level and the outflow hydrograph from the dam has a peak rate of $8.875 \mathrm{~m}^{3} / \mathrm{s}$. The flooding volume is approximately 73 times less than the respected volume in the Tous Dam break case. Ürkmez, Turkey, is located $2-\mathrm{km}$ downstream of the dam body and the total affected downstream area is approximately $5 \mathrm{~km}^{2}$, which is 60 times less than the affected downstream area in the Tous Dam collapse case. Experimental results presented revealed that depths can reach $2 \mathrm{~m}$ downtown, which is 3.5 times shallower than that in the Tous Dam break case. This result seems reasonable in the sense that there is almost 73 times more volume of flooding water, 60 times larger affected area, and Sumacercel, Spain, is $5-\mathrm{km}$ downstream of Tous Dam.

\section{Conclusions}

A distorted physical model of Ürkmez Dam was designed and built in order to study the flood propagation due to partial dam break resulting from a trapezoid-shaped breach. The physical model reflected the whole topography of the area, the reservoir, the dam body, and the downstream area, including the creek, the highway, and the buildings. Water levels were measured at eight different locations by e+ WATER L level sensors. The flow velocities were measured at four different locations by UVP and its transducers. The flood propagation was recorded by an HD camera. There were no significant backwater effects within the reservoir resulting from the lift of the trapezoidal section by the motor and the experiments were repeatable.

The experimental results revealed that in such a collapse the flood arrives at the main road in $2 \mathrm{~min}$ and to the sea cost in $4 \mathrm{~min}$ in prototype. The maximum water depths measured in the physical model ranged from 3.82 to $9.88 \mathrm{~cm}$, corresponding to 1.15 - and $2.96-\mathrm{m}$ flood depth in the prototype that can flood Ürkmez, Turkey. The maximum velocities ranged from $30.97 \mathrm{~m} / \mathrm{s}$ (close to dam body) to $0.78 \mathrm{~m} / \mathrm{s}$ (in dense residential areas) in the prototype. High velocities can cause serious damage in the buildings close to the dam body. In approximately $6 \mathrm{~min}$, the first floor of the residential areas can be submerged under water, causing extensive damage and loss of life in a very short time. Water levels in residential areas downtown would reach $3 \mathrm{~m}$ in $6 \mathrm{~min}$ and stay at nearly the same level for approximately $15 \mathrm{~min}$ before it starts receding. The recession in residential areas takes longer due to the storage effects of the buildings. This delay is more prolonged in the locations that are near the road. In the first 6 min of the dam break, flow depths can reach $1.5 \mathrm{~m}$ in the residential area at the end of the town.

Flow velocities reach $70 \mathrm{~km} / \mathrm{h}$ in sparse residential areas, close to the dam body. Velocities lose their effect in sparse residential areas away from the dam body. In dense residential areas, the velocities were very low. Hence, the buildings in very sparse residential areas close to the dam body can experience the highest amount of hydrodynamic pressure forces as opposed to the ones in dense residential areas downtown.

In sparse residential areas close to the dam body, flow depths and velocities reach their respective peak values at approximately the same time. They had similar rising and recession profiles. In very dense residential areas, due to the effects of building blocks, while velocity fluctuated at very low magnitude, flow depth kept rising.

Vertical variations of velocities showed markedly different behavior during rising and recession stages. The profiles were smooth during the rising stage in sparse residential areas, yet they showed fluctuating behavior during the recession stage. This behavior can also be observed in dense residential areas in which flow velocities were very low and flow depths were very high.

The experimental results presented in this study can be used for the numerical modeling works of dam break flows in urban areas.

As future work, the physical model could be built in a more comprehensive way by introducing more roughness elements representing vegetative cover. Furthermore, experiments could be carried out over movable bed where the influence of Ürkmez Creek erosion on the flooding in the downstream area could be observed. Last, the dam body could be built as a compacted material and thus 
the influence of sediment from the dam body and the dead storage on the downstream flooding area could be investigated.

\section{Acknowledgments}

This study is financially supported by Turkish Science and Technological Research Council (TÜBİTAK) through the 110M240 project. We deeply thank TUBITAK. Our gratitude goes to İzmir Municipality and IZSU Administration for their contributions on the acquisition of the required drawings and the relevant maps. The writers would also like to thank Professor Dr. Turhan Acatay for his valuable advice.

\section{Supplemental Data}

Fig. S1 is available online in the ASCE Library (http://www .ascelibrary.org).

\section{References}

Alcrudo, F., and Mulet, J. (2007). "Description of the Tous Dam break case study." J. Hydraul. Res., 45, 45-57.

Bozkus, Z. (2004). "Dam break analysis for disaster management." IMO Teknik Dergi, 15(4), 3335-3350 (in Turkish).

Cagatay, H., and Kocaman, S. (2008). "Experimental study of tailwater level effects on dam break flood wave propagation." Riverflow2008, Vol. 1, M. S. Altinakar, M. A. Kökpınar, I. Aydın, S. Çokgör, and S. Kırkgöz, eds., Kubaba, Ankara, Turkey, 635-644.

Eijelkamp Agrisearch Equipment. (2014). "e+ WATER L (Level) sensor.” (http://en.eijkelkamp.com/products/water/hydrological-research/water -level-measurements〉 (Jun. 4, 2014).

Frazao, S. S. (2007). "Experiments of dam break wave over a triangular bottom sill." J. Hydraul. Res., 45, 19-26.

Frazao, S. S., and Zech, Y. (2007). "Experiments of dam break flow against an isolated obstacle." J. Hydraul. Res., 45, 27-36.

Greco, M., Pontillo, M., Iervolino, M., and Leopardi, A. (2008). "2DH numerical simulation of breach evolution in an earth dam." Riverflow2008, Vol. 1, M. S. Altinakar, M. A. Kökpınar, I. Aydın, S. Çokgör, and S. Kırkgöz, eds., Kubaba, Ankara, Turkey, 661-667.

LaRocque, L. A., Elkholy, M., Chaudhry, M. H., and Imran, J. (2013b). "Experiments of urban flooding caused by a levee breach." J. Hydraul. Eng., 10.1061/(ASCE)HY.1943-7900.0000754, 960-973.

LaRocque, L. A., Imran, J., and Chaudhry, M. H. (2013a). "Experimental and numerical investigation of two-dimensional dam-break flows." J. Hydraul. Eng., 10.1061/(ASCE)HY.1943-7900.0000705, 569-579.

Lauber, G., and Hager, W. (1998). "Experiments to dam break wave: Horizontal channel." J. Hydraul. Res., 36(3), 291-307.

Leal, J. G. A. B., Ferreira, R. M. L., Franco, A. B., and Cardoso, A. H. (2002). "Dam-break waves on movable beds." Riverflow 2002, Vol. 2, D. Bousmar, and Y. Zech, eds., Swets \& Zeitlinger, Lisse, Netherlands, 981-990.

Map Data: Google, DigitalGlobe. (2013). 〈http://maps.google.com〉 (Oct. 14, 2012).

Met-Flow. (2002). UVP monitor model UVP-duo with software version 3, user guide, Met-Flow, S.A. Lausanne, Switzerland.

Met-Flow. (2014). "Transducers." 〈http://www.met-flow.com/index.php ?id=24〉 (Jun. 4, 2014).

Minussi, R. B., and Maciel, G. F. (2008). "Dam break problem-complete solution and shallow water approximation comparison." Riverflow2008, Vol. 1, M. S. Altinakar, M. A. Kökpınar, I. Aydın, S. Çokgör, and S. Kırkgöz, eds., Kubaba, Ankara, Turkey, 619-626.

Molu, M. (1995). "Dam-break flood in a natural channel: A case study." M.Sc. thesis, Civil Engineering Dept., Middle East Technical Univ., Ankara, Turkey.

Morris, M. W., Hassan, M. A. A. M., and Samuels, P. G. (2008). "Development of the HR BREACH model for predicting breach growth through flood embankments and embankment dams." Riverflow2008, Vol. 1, M. S. Altinakar, M. A. Kökpınar, I. Aydın, S. Çokgör, and S. Kırkgöz, eds., Kubaba, Ankara, Turkey, 679-687.

Palumbo, A., Soares-Frazao, S., Goutiere, L., Pianese, D., and Zech, Y. (2008). "Dam-break flow on mobile bed in a channel with a sudden enlargement." Riverflow2008, Vol. 1, M. S. Altinakar, M. A. Kökpınar, I. Aydın, S. Çokgör, and S. Kırkgöz, eds., Kubaba, Ankara, Turkey, 645-654.

Testa, G., Zuccala, D., Alcrudo, F., Mulet, J., and Frazao, S. S. (2007). "Flash flow experiment in a simplified urban district." J. Hydraul. Res., $45,37-44$.

Vasquez, J. A., and Leal, J. G. B. (2006). "Two-dimensional dam-break simulation over movable beds with an unstructured mesh." Riverflow 2006, Vol. I, R. M. L. Ferreira, E. C. T. L. Alves, J. G. A. B. Leal, and A. H. Cardoso, eds., Taylor \& Francis, London, U.K., 1483-1491.

Vischer, V. L., and Hager, W. H. (1997). Dam hydraulics, Wiley, New York.

Yalın, M. S. (1971). Theory of hydraulic models, Macmillan Press, London.

Yanmaz, A. M., and Beşer, M. R. (2005). "On the reliability-based safety analysis of the Porsuk Dam." Turk. J. Eng. Environ. Sci., 29(5), 309-320.

Yochum, S. E., Goertz, L. A., and Jones, P. H. (2008). "The Big Bay Dam failure: Accuracy and comparison of breach predictions." J. Hydraul. Eng., 10.1061/(ASCE)0733-9429(2008)134:9(1285), 1285-1293. 